\title{
$\beta$-Carbolines. 2. Rate Constants of Proton Transfer from Multiexponential Decays in the Lowest Singlet Excited State of Harmine in Water As a Function of pH
}

\author{
A. Dias,$^{\dagger}$ A. P. Varela, ${ }^{\ddagger}$ M. da Graça Miguel,, R. S. Becker, ${ }^{\dagger}$, H. D. Burrows, ${ }^{\ddagger}$ and \\ A. L. Maçanita $*,+, \|$ \\ Instituto de Tecnologia Quimica e Biologica, Rua da Quinta Grande, no. 6-P-2780 OEIRAS, Portugal, \\ Departamento de Química, Universidade de Coimbra, Portugal, Department of Chemistry, University of \\ Arkansas, Fayetteville, Arkansas, and Departamento de Química do Instituto Superior Técnico, \\ Lisboa, Portugal
}

Received: May 14, 1996; In Final Form: August 23, $1996^{\otimes}$

\begin{abstract}
The $\beta$-carbolines present a complex problem involving multiple equilibria in the excited state in hydrogenbonding solvents including water. Three excited state species exist: neutral, cation, and zwitterion. Here we examine the multiple equilibria and excited state kinetics of harmine, using time-resolved and steady state fluorescence techniques. From an analysis of the multiexponential decays, measured at the emission wavelengths of the three species as a function of the $\mathrm{pH}$, seven unknowns (four rate constants and three reciprocal lifetimes) were determined. Data analysis was made both by a previously reported numerical method and by analytical solution of the differential equation set. The results obtained accurately describe the independently obtained steady-state fluorescence results. The dramatic modifications of the equilibria and rate constants between the ground and excited states can be understood on the basis of the significative changes in charge densities on the two nitrogen atoms of harmine upon excitation. Mechanisms are proposed for the formation of excited state cation and zwitterion beginning with the excited state neutral molecule.
\end{abstract}

\section{Introduction}

Harmine (7-methoxy-1-methyl-9H-pyrido[3,4- $b$ ]indole) is a natural alkaloid belonging to the $\beta$-carbolines group occurring in a number of plants ${ }^{1,3}$ and presenting biological and pharmacological interest. ${ }^{4,5}$

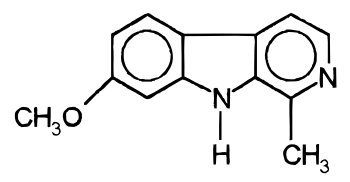

Recently we published a comprehensive photophysical study of these compounds in several classes of organic solvents. ${ }^{6}$ This included absorption spectra, excited singlet state equilibria, nature of the tautomers present, quantum yields, and lifetimes of fluorescence and a correlation of these with theoretical calculations regarding transition energies and charge densities. ${ }^{6}$ Briefly, we were able to show that only a single excited species (the neutral form) was present in nonpolar (as hexane) and even polar aprotic solvents (as acetonitrile). In protic solvents like methanol, three species exist: neutral, cation, and zwitterion (except for harmaline). In the case of exclusive excitation of the cation $\left(\lambda_{\mathrm{ex}}=356 \mathrm{~nm}\right)$, only one species existed in $\mathrm{S}_{1}$ which was the cationic form. Transition energies were well predicted from molecular orbital calculations (INDO/S-CI), and a dramatic change of charge density on the different nitrogen atoms of the neutral form on going from the ground to the lowest excited singlet state helped to rationalize the existence of the species observed. Finally, we considered a kinetic model for the observed complex decays arising from multiple excited state

\footnotetext{
† Instituto de Tecnologia Química e Biologica.

¥ Universidade de Coimbra.

$\S$ University of Arkansas.

"Departamento de Química do Instituto Superior Técnico.

${ }^{\otimes}$ Abstract published in Advance ACS Abstracts, October 1, 1996.
}

tautomers. However, we did not develop a full treatment to evaluate the interconversion rate constants.

Others have examined some aspects of the emission and the existence of tautomers of some $\beta$-carbolines in water including $\mathrm{pH}$ dependence. ${ }^{7-10}$ Also, time-correlated techniques have been employed to examine the fluorescence decays of norharmane in water as a function of $\mathrm{pH} \cdot{ }^{11-13}$ An analysis of the excited state interconvertion kinetics between tautomers and an evaluation of the rate constants were presented. ${ }^{13}$ However, we believe that both the data and the analysis published ${ }^{13}$ are not correct for reasons presented in ref 14.

In this paper, we shall examine harmine behavior as a function of $\mathrm{pH}$, using time-correlated single-photon counting techniques and an expanded kinetic model to obtain seven unknowns: four rate constants and three reciprocal lifetimes, from three decay times and two amplitude ratios. A comprehensive discussion of these results will be accomplished utilizing MO calculations.

\section{Experimental Section}

Harmine (Aldrich) was used as purchased. The absence of fluorescent impurities was ascertained by TLC and from the observation of single-exponential decays in several nonprotic solvents. Water was twice distilled and passed through a millipore column (Milli-Q Standard System). The $\mathrm{pH}$ of the solutions at $20{ }^{\circ} \mathrm{C}$ was measured with a Crison micropH 2002 $\mathrm{pH}$ meter. The $\mathrm{pH}$ adjustments were accomplished by addition of $\mathrm{NaOH}$ or $\mathrm{HCl}$. The most concentrated solutions of $\mathrm{NaOH}$ or $\mathrm{HCl}$ without harmine were free from fluorescent impurities. Harmine concentration was $2.5 \times 10^{-5} \mathrm{M}$ unless stated otherwise, and the solutions were deoxygenated by argon or nitrogen bubbling. The solutions remained stable in the course of the measurements.

Absorption and fluorescence spectra were measured with a Beckman DU-70 spectrometer and SPEX Fluorolog Spectrofluorimeter, respectively. All fluorescence spectra were corrected. Fluorescence quantum yields were measured as in ref 6.

(C) 1996 American Chemical Society 


\section{SCHEME 1}

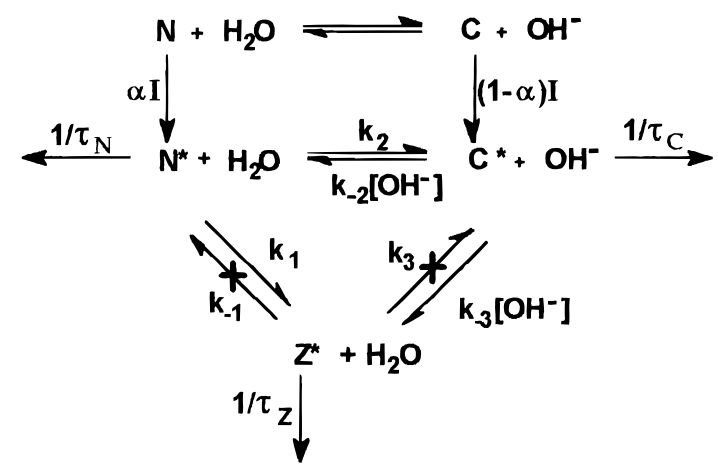

Fluorescence decays were obtained using the time-correlated single-photon counting technique as previousely described. ${ }^{15,16}$ The excitation wavelength was 337 or $356 \mathrm{~nm}$, and the emission bandwidths were $4 \mathrm{~nm}$. Alternate measurements $\left(10^{3}\right.$ counts at the maximum per cycle) of the pulse profile and the sample emission were done until $3 \times 10^{4}$ counts at the maximum were reached. The photomultiplier wavelength shift was $0.3 \mathrm{ps} / \mathrm{nm}$ in the wavelength region of the interest. Some of the decays were repeated by replacing the nanosecond flash lamp with an argon ion pumped, frequency-tripled $\mathrm{Ti} /$ sapphire picosecond laser system from Spectra Physics, Inc. $\left(\lambda_{\mathrm{ex}}=287 \mathrm{~nm}\right.$; pulse rate $=827 \mathrm{kHz}$ ). In these measurements the pulse fwhm was reduced to $\approx 400 \mathrm{ps}$. The fluorescence decays were deconvoluted with a $\mu \operatorname{Vax} 2000$ or 3100 computer using the modulation functions method with shift correction. ${ }^{17}$

Standart molecular orbital calculations of the ground and excited states properties (atomic charge densities and states energies) of the three forms of harmine were done using the AM1/MECI method with optimization of geometries (AMPAC package).

\section{Kinetic Model}

It will be shown later in the results section that the excited state processes of harmine in $\mathrm{H}_{2} \mathrm{O}$ can be interpreted with the kinetic scheme shown in Scheme 1, where $\mathrm{N}$ is neutral harmine, $\mathrm{C}$ is cation, $\mathrm{Z}$ is zwitterion, and * refers to the lowest excited singlet state. In this scheme, $\alpha$ is the fraction of light absorbed by the neutral form, $\tau_{\mathrm{N}}, \tau_{\mathrm{C}}$, and $\tau_{\mathrm{Z}}$, are the fluorescence lifetimes of the neutral, cationic, and zwitterionic forms, respectively, $k_{1}$ and $k_{2}$ are pseudo-unimolecular rate constants $\left.\left(k_{i}=k_{i}^{\prime}\left[\mathrm{H}_{2} \mathrm{O}\right]\right)\right)$ and $k_{-2}$ and $k_{-3}$ are the bimolecular rate constants for the $\mathrm{OH}^{-}$mediated deprotonation of the cation to give the neutral or the zwitterionic forms, respectively. The rate constants of the zwitterion reactions $k_{-1}\left(\mathrm{Z}^{*}\right.$ to $\left.\mathrm{N}^{*}\right)$ and $\mathrm{k}_{3}\left(\mathrm{Z}^{*}\right.$ to $\left.\mathrm{C}^{*}\right)$ are negligible with respect to $1 / \tau_{\mathrm{Z}}$ (see below).

Solution of the Differential Equations. The time evolution of the excited state concentrations of $\mathrm{N}^{*}, \mathrm{C}^{*}$, and $\mathrm{Z}^{*}$ under pulse excitation are defined by the following set of differential equations

$$
\frac{\mathrm{d}}{\mathrm{d} t}\left[\begin{array}{l}
\mathrm{N}^{*} \\
\mathrm{C}^{*} \\
\mathrm{Z}^{*}
\end{array}\right]=\left[\begin{array}{lll}
-X & k_{-2}\left[\mathrm{OH}^{-}\right] & 0 \\
k_{2} & -Y & 0 \\
k_{1} & k_{-3}\left[\mathrm{OH}^{-}\right] & -Z
\end{array}\right] \times\left[\begin{array}{l}
N^{*} \\
C^{*} \\
Z^{*}
\end{array}\right]
$$

$$
\begin{gathered}
X=k_{1}+k_{2}+1 / \tau_{\mathrm{N}} \\
Y=\left(k_{-2}+k_{-3}\right)\left[\mathrm{OH}^{-}\right]+1 / \tau_{\mathrm{C}} \\
Z=1 / \tau_{\mathrm{Z}}
\end{gathered}
$$

The solutions have the general form ${ }^{19}$

$$
\left[x_{i}\right]=\sum_{j=1}^{3} a_{i j} \mathrm{e}^{-\lambda_{j} t} \quad(j=1,2,3)
$$

where the reciprocal decay times are

$$
\begin{gathered}
\lambda_{1}=1 / \tau_{\mathrm{Z}} \\
\lambda_{2,3}=\frac{X+Y \mp \sqrt{(X+Y)^{2}+4 k_{2} k_{-2}\left[\mathrm{OH}^{-}\right]}}{2}
\end{gathered}
$$

In the particular case of Scheme 1 , the amplitudes, $a_{i j}$, are obtained using the boundary conditions, $\sum_{j=1}^{3} a_{1 j}=\alpha, \sum_{j=1}^{3} a_{2 j}$ $=1-\alpha$, and $\sum_{j=1}^{3} a_{3 j}=0$ from which the following relationships are derived:

(i) For the neutral form, the amplitude of the longest decay component $\left(1 / \tau_{\mathrm{z}}\right)$ is equal to zero $\left(a_{11}=0\right)$ because the backreactions from $Z^{*}$ to $N^{*}$ (and $C^{*}$ ) are negligible with respect to the reciprocal lifetime of $\mathrm{Z}^{*}$. Under these conditions, the decays are predicted to be either single (at low $\left[\mathrm{OH}^{-}\right]$) or double exponentials (at high $\left[\mathrm{OH}^{-}\right]$)

$$
[\mathrm{N}](t)=a_{12} \mathrm{e}^{-\lambda_{2} t}+a_{13} \mathrm{e}^{-\lambda_{3} t}
$$

with

$$
\frac{a_{13}}{a_{12}}=\frac{\alpha\left(X-\lambda_{2}\right)-(1-\alpha) k_{-2}\left[\mathrm{OH}^{-}\right]}{\alpha\left(\lambda_{3}-X\right)+(1-\alpha) k_{-2}\left[\mathrm{OH}^{-}\right]}
$$

(ii) For the cation, the amplitude of the longest decay component $\left(1 / \tau_{\mathrm{z}}\right)$ is also equal to zero $\left(a_{21}=0\right)$ for the same reasons that $a_{11}=0$ (see above); i.e., also double-exponential decays are predicted

$$
[\mathrm{C}](t)=a_{22} \mathrm{e}^{-\lambda_{2} t}+a_{23} \mathrm{e}^{\lambda_{3} t}
$$

with

$$
\frac{a_{23}}{a_{22}}=\frac{\alpha+(1-\alpha) \frac{k_{-2}\left[\mathrm{OH}^{-}\right]}{\lambda_{2}-X}}{\alpha+(1-\alpha) \frac{k_{-2}\left[\mathrm{OH}^{-}\right]}{\lambda_{3}-X}}
$$

(iii) For the zwitterion, the amplitudes, $a_{i j}$, are all different from zero, leading to triple-exponential decays

$$
[\mathrm{Z}](t)=a_{31} \mathrm{e}^{-\lambda_{1} t}+a_{32} \mathrm{e}^{-\lambda_{2} t}+a_{33} \mathrm{e}^{-\lambda_{3} t}
$$

where

$$
\frac{a_{33}}{a_{32}}=\frac{\lambda_{2}-\lambda_{1}}{\lambda_{3}-\lambda_{1}}-\frac{k_{1}+\frac{k_{3} k_{-2}\left[\mathrm{OH}^{-}\right]}{X-\lambda_{3}}}{k_{1}+\frac{k_{3} k_{-2}\left[\mathrm{OH}^{-}\right]}{X-\lambda_{2}}} \times \frac{a_{13}}{a_{12}}
$$

where 


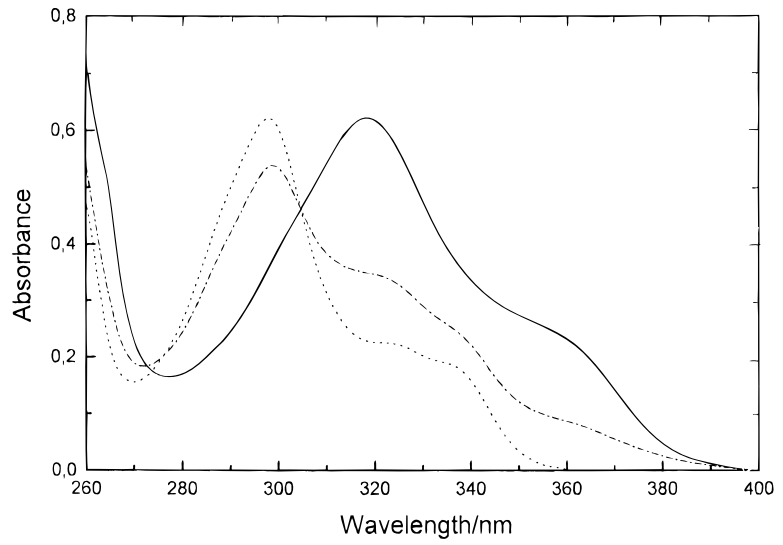

Figure 1. Absorption spectra of $3.2 \times 10^{-5} \mathrm{M}$ solutions of harmine in $\mathrm{H}_{2} \mathrm{O}$ at $\mathrm{pH}$ values: $(-) 6.8 ;(-\cdot-) 8.2 ;(\cdots)$ 10.4.

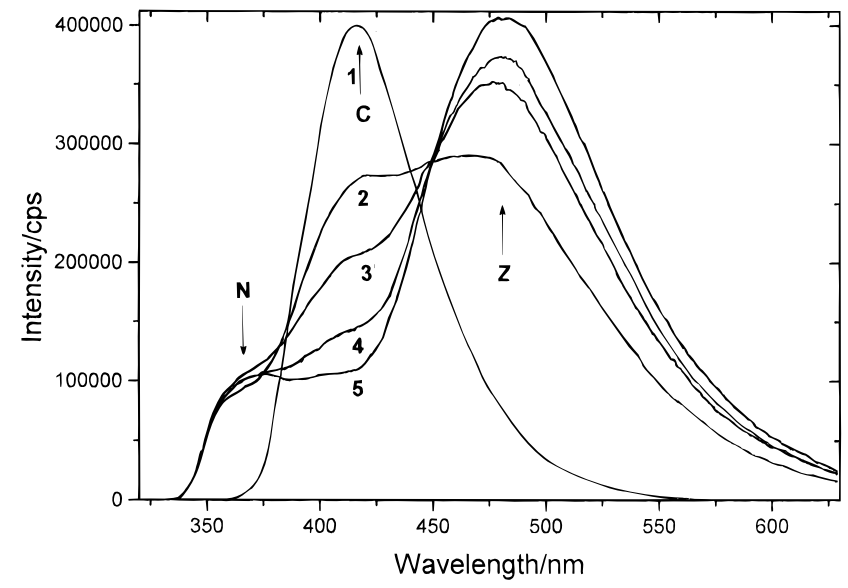

Figure 2. Fluorescence spectra of optically matched solutions of harmine in $\mathrm{H}_{2} \mathrm{O}\left(\lambda_{\mathrm{ex}}=337 \mathrm{~nm}\right)$ at several $\mathrm{pH}$ values: (1) 6.5 ; (2) 12.0 ; (3) 12.48 ; (4) 12.7 ; (5) 12.85 , at $20^{\circ} \mathrm{C}$.

Under steady-state conditions and exclusive excitation of $\mathrm{N}$ $(\alpha=1),\left(\mathrm{d}\left[X_{i}\right] / \mathrm{d} t=0\right)$, the neutral to cation fluorescence quantum yield ratio is derived from eq 1 as

$$
\frac{\phi_{\mathrm{N}}}{\phi_{\mathrm{C}}}=\frac{k_{\mathrm{f}}^{\mathrm{N}}}{k_{\mathrm{f}}^{\mathrm{C}}} \times \frac{1}{k_{2} \tau_{\mathrm{C}}}+\frac{k_{\mathrm{f}}^{\mathrm{N}}}{k_{\mathrm{f}}^{\mathrm{C}}} \times \frac{k_{-2}+k_{-3}}{k_{2}}\left[\mathrm{OH}^{-}\right]
$$

and the zwitterion to cation fluorescence quantum yield ratio is

$$
\frac{\phi_{\mathrm{Z}}}{\phi_{\mathrm{C}}}=\frac{k_{\mathrm{f}}^{\mathrm{Z}}}{k_{\mathrm{f}}^{\mathrm{C}}} \times \frac{k_{1} \tau_{\mathrm{Z}}}{k_{2} \tau_{\mathrm{C}}}+\frac{k_{\mathrm{f}}^{\mathrm{Z}}}{k_{\mathrm{f}}^{\mathrm{C}}} \times \frac{k_{1}\left(k_{-2}+k_{-3}\right)+k_{2} k_{-3}}{k_{2}} \tau_{\mathrm{Z}}\left[\mathrm{OH}^{-}\right]
$$

where $k_{\mathrm{f}}^{\mathrm{N}}, k_{\mathrm{f}}^{\mathrm{C}}$, and $k_{\mathrm{f}}^{\mathrm{Z}}$ are the neutral, cation, and zwitterion radiative constants, respectively. Equations 12 and 13 predict linear variations of the quantum yield ratios with $\left[\mathrm{OH}^{-}\right]$.

\section{Results and Discussion}

Absorption and Emission Spectra. Absorption spectra of harmine in water as a function of the $\mathrm{pH}$ are shown in Figure 1. Below $\mathrm{pH}=7$ the absorption is exclusively due to the cationic form. Between $\mathrm{pH}=7$ and $\mathrm{pH}=9.5$, the absorption spectra is the sum of the neutral and cationic absorption spectra, and above $\mathrm{pH}=9.5$ only the neutral form absorbs.

Fluorescence spectra as a function of the $\mathrm{pH}\left(\lambda_{\mathrm{ex}}=337 \mathrm{~nm}\right)$ are given in Figure 2. Below $\mathrm{pH}=7.0$, only the cation emission, centered at $400 \mathrm{~nm}$, is observed. Upon increase of

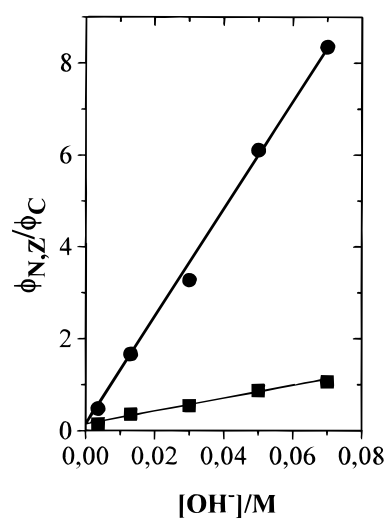

Figure 3. Plots of the neutral to cation, $\phi_{\mathrm{N}} / \phi_{\mathrm{C}}(\square)$, and zwitterion to cation, $\phi_{\mathrm{Z}} / \phi_{\mathrm{C}}(\mathbf{)})$, fluorescence quantum yields ratios of harmine in $\mathrm{H}_{2} \mathrm{O}$, at $20^{\circ} \mathrm{C}, \lambda_{\mathrm{ex}}=337 \mathrm{~nm}$, as a function of $\left[\mathrm{OH}^{-}\right]$.

the $\mathrm{pH}$, two new emission bands appear: the neutral form emission $(350 \mathrm{~nm})$ and the zwitterion emission $(500 \mathrm{~nm})$.

The excitation spectrum run at the zwitterionic emission wavelength $\left(\lambda_{\mathrm{em}}=550 \mathrm{~nm}\right)$ is identical to the neutral form absorption which indicates that the zwitterion is formed exclusively by an excited state process with its origin being the neutral form, either $\mathrm{N}^{*} \rightarrow \mathrm{Z}^{*}$ and/or $\mathrm{N}^{*} \rightarrow \mathrm{C}^{*} \rightarrow \mathrm{Z}^{*}$. However, direct excitation of the cation $\left(\lambda_{\mathrm{ex}}=370 \mathrm{~nm}\right)$ at $\mathrm{pH} \leq 9.0$ produces only the cation emission. These results mean that below $\mathrm{pH}=9.0$, the zwitterion may be formed exclusively by $a$ double proton transfer mechanism: ${ }^{18} N^{*} \rightarrow Z^{*}$. Finally, above $\mathrm{pH}=13$ the cation emission vanishes.

The ratios of the fluorescence quantum yields, $\Phi_{N} / \Phi_{C}$ and $\Phi_{\mathrm{Z}} / \Phi_{\mathrm{C}}$, increase linearly with $\left[\mathrm{OH}^{-}\right]$, which is attributed to the deprotonation of the cation to give the neutral and/or the zwitterionic forms in the excited state, respectively (Figure 3).

Fluorescence Decays. The fluorescence decays from excitation $(337 \mathrm{~nm})$ of the neutralized form of harmine in water were measured as a function of the $\mathrm{pH}$ at four emission wavelengths: $350 \mathrm{~nm}$ (where only the neutral form emits), $400 \mathrm{~nm}$ (cation plus neutral forms), $450 \mathrm{~nm}$ (cation plus zwitterion), and $500 \mathrm{~nm}$ (mainly zwitterion). One typical set of decays is presented in Figure 4. The results derived from multiexponential fittings of the decays at several $\mathrm{pH}$ values are sumarized in Figure 5, where the decay times $\left(\tau_{j}=1 / \lambda_{j}\right)$ and the experimental preexponential factors $\left(A_{i j}\right.$, see later equations relating $a_{i j}$ to $\left.A_{i j}\right)$ at 350,400 , and $500 \mathrm{~nm}$ are shown.

Decays at $350 \mathrm{~nm}$ (Neutral Form). At $\lambda_{\mathrm{em}}=350 \mathrm{~nm}$, the decays are single exponentials up to $\mathrm{pH}=9$, Figure 4a. Under these conditions, it is assigned to the neutral form. This decay time ( $\left.\tau_{3}=0.41 \pm 0.03 \mathrm{~ns}\right)$ is 1 order of magnitude smaller than the fluorescence lifetime of harmine in nonprotic solvents (4.97 $\mathrm{ns}$ in dioxane or $4.65 \mathrm{~ns}$ in benzene, ${ }^{6}$ indicating an efficient fluorescence quenching of the neutral form in water. For higher $\mathrm{pH}$ values the decay fittings slightly improve with doubleexponential analysis $\left(A_{13} / A_{12}>100\right)$ and definitely become double exponential at $\mathrm{pH}>11.5\left(A_{13} / A_{12}<100\right)$. The component time with the largest amplitude has the shortest decay time $\left(\tau_{3}\right)$ and remains $\mathrm{pH}$ independent within the experimental accuracy. The second decay time $\left(\tau_{2}\right)$, which will be shown to be identical to the cation major component (see decays at 400 $\mathrm{nm})$, decreases from $7.1 \mathrm{~ns}(\mathrm{pH}=9.5)$ down to $1.5 \mathrm{~ns}(\mathrm{pH}=$ 13 ), and the amplitude of $\tau_{2}$ in the neutral decay $\left(A_{12}\right)$ increases due to the increase of the cation back-reaction to form the neutral in the same $\mathrm{pH}$ range. The increase of $A_{12}$ with the increase in pH clearly indicates that at sufficiently high $\mathrm{OH}^{-}$concentration the excited state cation can be deprotonated in a back-reaction to give the neutral form, in the excited state. Finally, at very 

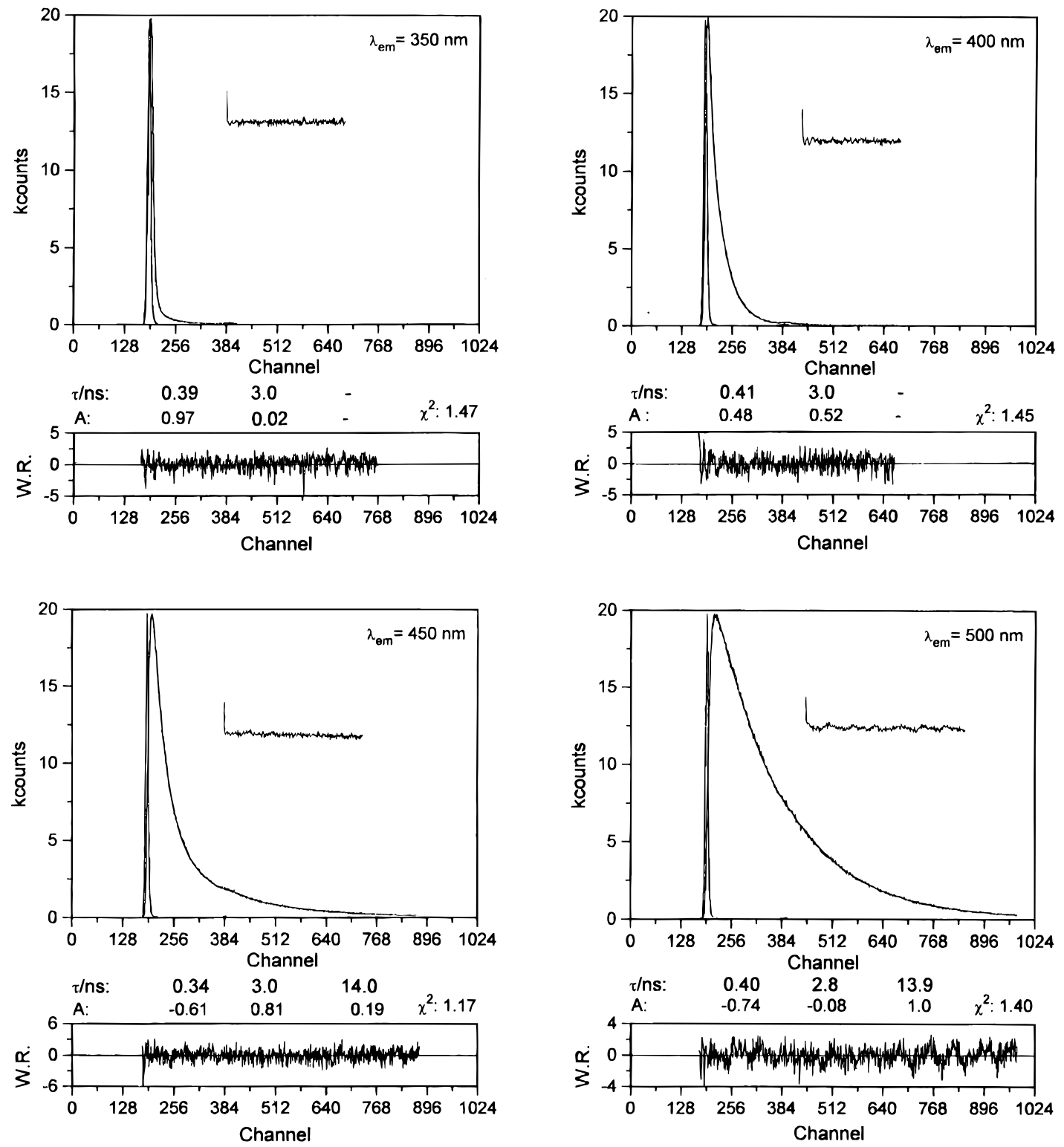

Figure 4. Fluorescence decays of harmine $\left(\lambda_{\mathrm{ex}}=337 \mathrm{~nm}\right)$ in $\mathrm{H}_{2} \mathrm{O}, \mathrm{pH}=12.2$, at $20{ }^{\circ} \mathrm{C}$, at four emission wavelengths: 370 , 400 , 450 , and 500 $\mathrm{nm}$. Also shown are the weighted residuals (W.R.), the autocorrelation functions (AC), $\chi$-squared values $\left(\chi^{2}\right)$, decay times, and amplitudes for each decay.

high $\mathrm{pH}$ values $(\mathrm{pH}>12.5)$ triple-exponential fittings become better than double. The third decay time $\left(\tau_{1}\right)$ is identical to the major zwitterion decay time (see decays at $500 \mathrm{~nm}$ ). It should be noted, however that this component hardly appears $\left(A_{13} / \mathrm{A}_{11}\right.$ $>1000$ ), which means that the excited state back-reaction from the zwitterion to the neutral form is extremely slow when compared with the zwitterionic reciprocal lifetime. Under such conditions this back-reaction can be ignored in the kinetic analysis.

Decays at $400 \mathrm{~nm}$ (Cation Plus Neutral). The decays at 400 $\mathrm{nm}$, with excitation at $337 \mathrm{~nm}$, are double exponentials at practically all $\mathrm{pH}$ values. The shorter decay time $\left(\tau_{3}\right)$ is identical to the one observed at $350 \mathrm{~nm}$ (neutral form) appearing as a decay (positive amplitude) (Figure 4c). The longer decay time $\left(\tau_{2}\right)$ now has the largest amplitude and has the same $\mathrm{pH}$ dependence as that discussed above for the neutral form. At $\mathrm{pH}$ values lower than 9.0, excitation at $356 \mathrm{~nm}$ (where only the cation absorbs) produces a single-exponential decay, which is attributed solely to the cation, with a decay time equal to 7.14 ns. This is identical to the decay time $\tau_{2}$ which is observed with excitation at $337 \mathrm{~nm}$ (neutral form excitation) and $\lambda_{\mathrm{em}}=$ $350,400,450$, or $500 \mathrm{~nm}$, below $\mathrm{pH}=9$. The absence of the zwitterion decay time $\left(\tau_{1}\right)$ (see below) indicates that the excited zwitterion does not return to give the excited state cation.

Decays at 450 and $500 \mathrm{~nm}$ (Zwitterion Plus Cation). The decays at 450 or $500 \mathrm{~nm}$ are triple exponentials at all $\mathrm{pH}$ values. Two of the three decay times are identical to those observed at shorter wavelengths $\left(\tau_{3}\right.$ and $\left.\tau_{2}\right)$. The third one, $\tau_{1} \approx 14.3 \mathrm{~ns}$, is independent of the $\mathrm{pH}$ and is assigned to the fluorescence lifetime of the zwitterionic form. The shortest component $\left(\tau_{3}\right)$, $\mathrm{N}^{*}$, appears always as a rise time $\left(A_{33}<0\right)$, while the amplitude associated with $\tau_{2}\left(A_{32}\right), \mathrm{C}^{*}$, is positive up to $\mathrm{pH}=11.2$. At higher $\mathrm{pH}$ values $(\mathrm{pH} \geq 11.7), \mathrm{A}_{32}<0$; i.e., $\tau_{2}$ also appears as a rise time (see Figure $5 \mathrm{~d}$ ). For all $\mathrm{pH}$ values the sum of the three amplitudes approach zero, i.e., $\sum_{j=1}^{3} A_{3 j}=0$; see Figure $4 \mathrm{c}$. The results mean that, at sufficiently large $\mathrm{OH}^{-}$concentrations, the zwitterion is formed in the excited state from the cation (as well as the neutral).

Finally, with excitation at $356 \mathrm{~nm}$ (where only the cation absorbs), at $\mathrm{pH}$ values lower than 9.0, the decays at the cation emission wavelength are single-exponential decays. This observation, plus the fact the neutral form produces both cation and zwitterion, confirms our previous assumption that, at $\mathrm{pH}$ 

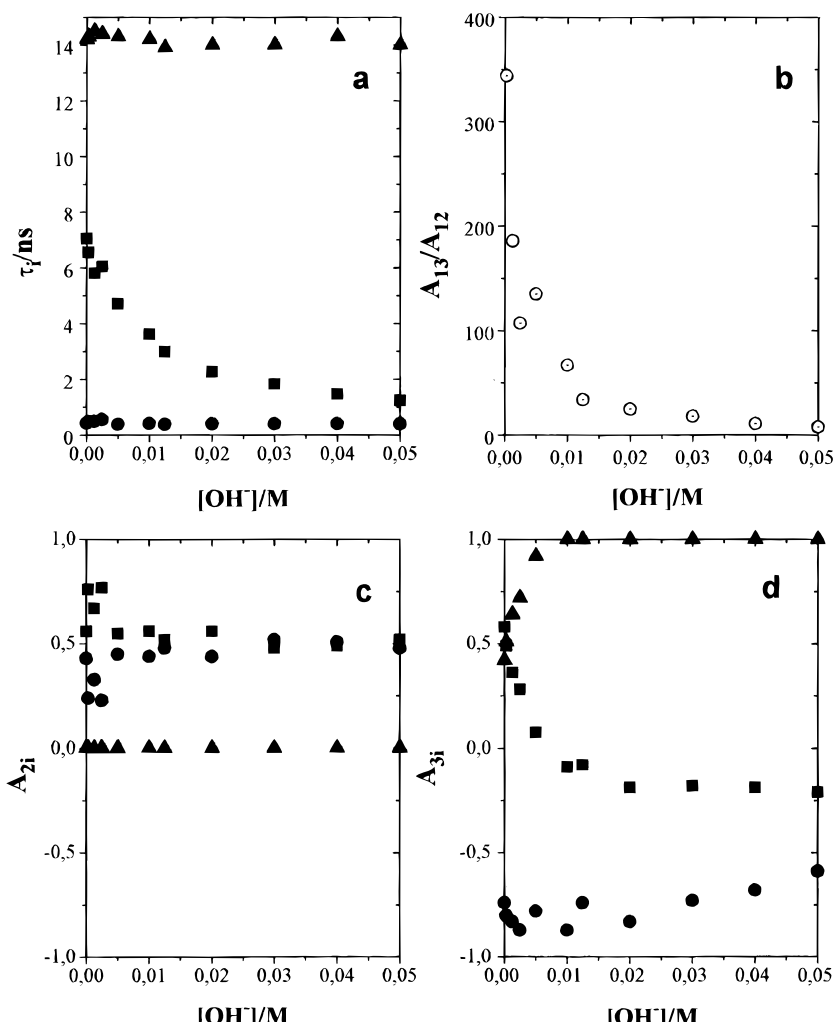

Figure 5. Plot of (a) the decay times $\left(\tau_{i}\right)$, (b) amplitudes ratio at 350 $\mathrm{nm}\left(A_{13} / A_{12}\right)$, and amplitudes $\left(A_{i j}\right)$ at (c) $400 \mathrm{~nm}$ and (d) $500 \mathrm{~nm}$.

values lower than 9.0, the zwitterion is formed directly from the excited neutral form.

Therefore, from the prior results in water, the following conclusions can be derived: (i) the excited neutral form can produce both the cation and zwitterion; (ii) the excited zwitterion does not form either the excited neutral or excited cation; (iii) the excited cation can be deprotonated by $\mathrm{OH}^{-}$to form either the excited neutral or the zwitterion. Under these conditions, the results can be analyzed with the kinetics derived from the mechanism in Scheme 1 given earlier.

Data Analysis. The fluorescence decays at 400 and $500 \mathrm{~nm}$ correspond to more than one emitting species in general. At $400 \mathrm{~nm}$ there are contributions of the neutral and cationic forms, and at $500 \mathrm{~nm}$ both the cation and the zwitterion emit.

The fluorescence decays at $400 \mathrm{~nm}$ are written as

$$
I_{400}(t)=I_{400}^{\mathrm{N}}(t)+I_{400}^{\mathrm{C}}(t)=f_{400}^{\mathrm{N}}\left[\mathrm{N}^{*}\right](t)+f_{400}^{\mathrm{C}}\left[\mathrm{C}^{*}\right](t)
$$

where $f_{400}^{\mathrm{N}}$ is the product of the radiative rate constant, $k_{\mathrm{f}}^{\mathrm{N}}$, and the neutral form fluorescence intensity at $400 \mathrm{~nm}$ divided by the integrated fluorescence intensity of the neutral form over the entire fluorescence spectrum

$$
f_{400}^{\mathrm{N}}=k_{\mathrm{f}}^{\mathrm{N}} \frac{I_{400}^{\mathrm{N}}}{\int_{0}^{\infty} I^{\mathrm{N}}(\lambda) \mathrm{d} \lambda}
$$

and $f_{400}^{\mathrm{C}}$ has an analogous definition for the cation

$$
f_{400}^{\mathrm{C}}=k_{\mathrm{f}}^{\mathrm{C}} \frac{I_{400}^{\mathrm{C}}}{\int_{0}^{\infty} I^{\mathrm{C}}(\lambda) \mathrm{d} \lambda}
$$

At $500 \mathrm{~nm}$ both the cation and the zwitterion contribute to the fluorescence, i.e.

$$
I_{500}(t)=I_{500}^{\mathrm{Z}}(t)+I_{500}^{\mathrm{C}}(t)=f_{500}^{\mathrm{Z}}\left[\mathrm{Z}^{*}\right](t)+f_{500}^{\mathrm{C}}\left[\mathrm{C}^{*}\right](t)
$$

where $f_{500}^{Z}$ and $f_{500}^{C}$ are defined parallel to that in eqs 15 and 16 . Normalization of the fluorescence intensity at $t=0$ gives

$$
I_{400}(t)=\left(1-\beta_{1}\right)\left[\mathrm{N}^{*}\right](t)+\beta_{1}\left[\mathrm{C}^{*}\right](t)
$$

and

$$
I_{500}(t)=\beta_{2}\left[\mathrm{C}^{*}\right](t)+\left(1-\beta_{2}\right)\left[\mathrm{Z}^{*}\right](t)
$$

where

$$
\beta_{1}=\frac{f_{500}^{\mathrm{C}}}{f_{400}^{\mathrm{C}}+f_{400}^{\mathrm{N}}}
$$

and

$$
\beta_{2}=\frac{f_{500}^{C}}{f_{500}^{C}+f_{500}^{Z}}
$$

Substitution of eqs 6 and 8 in eq 18 gives

$$
\begin{aligned}
I_{400}(t)=a_{13}\left(1-\beta_{1}+\frac{a_{23}}{a_{13}} \beta_{1}\right) \mathrm{e}^{-\lambda_{3} t}+ & \\
& a_{12}\left(1-\beta_{1}+\frac{a_{22}}{a_{12}} \beta_{1}\right) \mathrm{e}^{-\lambda_{2} t}
\end{aligned}
$$

and replacing $a_{23} / a_{13}$ and $a_{22} / a_{12}$ one obtains

$$
\begin{aligned}
& I_{400}(t)=a_{13}\left(1-\beta_{1}+\beta_{1} \frac{X-\lambda_{3}}{k_{-2}\left[\mathrm{OH}^{-}\right]}\right) \mathrm{e}^{-\lambda_{3} t}+ \\
& a_{12}\left(1-\beta_{1}+\beta_{1} \frac{X-\lambda_{2}}{k_{-2}\left[\mathrm{OH}^{-}\right]}\right) \mathrm{e}^{-\lambda_{2} t}=A_{23} \mathrm{e}^{-\lambda_{3} t}+A_{22} \mathrm{e}^{-\lambda_{2} t}
\end{aligned}
$$

where $A_{23}$ and $A_{22}$ are the experimental amplitudes at $400 \mathrm{~nm}$.

Therefore, the experimental amplitude ratio at $400 \mathrm{~nm}\left(A_{23} /\right.$ $\left.A_{22}\right)$ is related to the amplitude ratio at $350 \mathrm{~nm}\left(A_{13} / A_{12}=a_{13} /\right.$ $\left.a_{12}\right)$ by

$$
\frac{A_{23}}{A_{22}}=\frac{A_{13}}{A_{12}} \frac{1-\beta_{1}+\beta_{1} X_{3}}{1-\beta_{1}+\beta_{1} X_{2}}=B
$$

where

$$
X_{3}=\frac{X-\lambda_{3}}{k_{-2}\left[\mathrm{OH}^{-}\right]}
$$

and

$$
X_{2}=\frac{X-\lambda_{2}}{k_{-2}\left[\mathrm{OH}^{-}\right]}
$$

Rewriting eq 7 with eqs 25 and 26 one obtains

$$
\frac{A_{13}}{A_{12}}=\frac{1-\alpha\left(1+X_{2}\right)}{\alpha\left(1+X_{3}\right)-1}=A
$$

and combining eqs 24 and 27, the values of $X_{2}$ and $X_{3}$ are determined 


$$
\begin{gathered}
X_{2}=\frac{\frac{1-\beta_{1} A}{\beta_{1}}(A-B)+\frac{1-\alpha}{\alpha}(A+1)}{B+1}-1 \\
X_{3}=\frac{\frac{(1-\alpha) A+1}{\alpha}+\left(1+X_{2}\right)}{A}
\end{gathered}
$$

From the definition of $X_{3}$ (eq 25) and $X_{2}$ (eq 26), one finally obtains

$$
X=\frac{X_{3} \lambda_{2}-X_{2} \lambda_{3}}{X_{3}-X_{2}}
$$

and

$$
k_{-2}\left[\mathrm{OH}^{-}\right]=\frac{X-\lambda_{2}}{X_{2}}
$$

Further relationships must be recalled in order to calculate values for $Y, k_{-3}, k_{1}$, and $k_{2}$, i.e., from eq 5

$$
Y=\lambda_{2}+\lambda_{3}-X
$$

from eq 2. $\quad k_{-3}\left[\mathrm{OH}^{-}\right]=Y-k_{2}\left[\mathrm{OH}^{-}\right]-1 / \tau_{\mathrm{C}}$

from eq 5. $\quad k_{2}=\frac{\left(\lambda_{3}-\lambda_{2}\right)^{2}-(X-Y)^{2}}{4 k_{-2}\left[\mathrm{OH}^{-}\right]}$

and from eq $2 \quad k_{1}=X-k_{2}-1 / \tau_{\mathrm{N}}$

In order to evaluate $\beta_{1}$ and $\beta_{2}$, the intrinsic fluorescence quantum yields $\left(\phi_{\mathrm{F}}{ }^{\circ}=k_{\mathrm{f}} /\left(k_{\mathrm{f}}+k_{\mathrm{nr}}\right)\right)$ and the unquenched fluorescence lifetimes $\left(\tau_{\mathrm{f}}^{\circ}=1 /\left(k_{\mathrm{f}}+k_{\mathrm{nr}}\right)\right.$, at $20^{\circ} \mathrm{C}$ are needed to calculate the radiative rate constants which in turn are needed to determine f values (see eqs 15 and 16). In the cation case, the radiative rate constants were readily obtained with direct excitation of the cation at sufficiently low $\mathrm{pH}$ values. However this was not possible for the other two forms since there is always fluorescence quenching of the neutral form in water and the zwitterion does not exist in the ground state. A first evaluation of $k_{\mathrm{f}}$ (neutral) has been made, given the observation that the fluorescence lifetime of the neutral form remains approximately constant in dioxane:water mixtures with water contents lower than $40 \%$ (4.7 ns in dioxane and $4.9 \mathrm{~ns}$ in 3:2 dioxane:water mixture at $\mathrm{pH}=6.5)$. On this basis, we assumed $k_{\mathrm{f}}$ and $k_{\mathrm{nr}}$ in dioxane are also valid for water (we will see below that this assumption is only slightly invalid and can only be corrected for after consideration of both steady state and time resolved data). With this data, the intrinsic fluorescence quantum yield of the zwitterion can be evaluated from the quantum yields of the three forms obtained from the decomposition of the total emission spectrum. ${ }^{19}$ Finally, all the considerations given above pointing to the irreversibility of the interconversion of the zwitterion back to either excited cation or neutral and the observation that the longest decay time observed in water $\left(\tau_{1}\right)$ does not change with the $\mathrm{pH}$, leads us to assign the decay time $\tau_{1}$ to the fluorescence lifetime of the zwitterion. With this $\tau_{1}$ and the fluorescence quantum yield, both the radiative $\left(k_{\mathrm{f}}\right)$ and the sum of the radiationless $\left(k_{\mathrm{nr}}\right)$ rate constants for the zwitterion were evaluated (Table 1). Using the data of Table 1 in eqs 15 and 16 , the values $\beta_{1}=0.48$ and $\beta_{2}=0.34$ were evaluated.

The rate constants in Scheme 1 were then calculated analyzing the data shown in Figure 5 with eqs $28-35$ and using for the
TABLE 1: Intrinsic Fluorescence Quantum Yields $\left(\phi_{\mathrm{f}}\right)$ and Lifetimes $\left(\tau_{\mathrm{f}}\right)$ and Radiative and Radiationless Rate Constants of the Neutral, Cationic, and Zwitterionic Forms of Harmine in Water, at $20^{\circ} \mathrm{C}$

\begin{tabular}{lccccc}
\hline & $\phi_{\mathrm{f}}$ & $\tau_{\mathrm{f}} / \mathrm{ns}$ & $k_{\mathrm{f}}^{a} / \mathrm{ns}^{-1}$ & $k_{\mathrm{nr}} / \mathrm{ns}^{-1}$ & $k_{\mathrm{f}}^{b} / \mathrm{ns}^{-1}$ \\
\hline neutral & $0.46^{c}$ & $4.7^{c}$ & 0.098 & 0.115 & 0.072 \\
cation & 0.49 & 7.1 & 0.069 & 0.072 & \\
zwitterion & $0.34^{d}$ & 14.3 & 0.024 & 0.046 & 0.025
\end{tabular}

${ }^{a}$ From $\phi_{\mathrm{f}} / \tau_{\mathrm{f}} \cdot{ }^{b}$ From $k^{N_{\mathrm{f}}} / k_{\mathrm{f}}^{\mathrm{C}_{\mathrm{f}}}=1.04$ and $k_{\mathrm{f}}^{\mathrm{f}_{\mathrm{f}}} / k_{\mathrm{f}}^{\mathrm{C}_{\mathrm{f}}}=0.35 .{ }^{c}$ In benzene. ${ }^{d}$ From $\left(\phi_{\mathrm{N}} / \phi_{\mathrm{N}}^{0}\right)+\left(\phi_{\mathrm{C}} / \phi_{\mathrm{C}}^{0}\right)+\left(\phi_{\mathrm{Z}} / \phi_{\mathrm{Z}}^{0}\right)=1$ (ref 19).
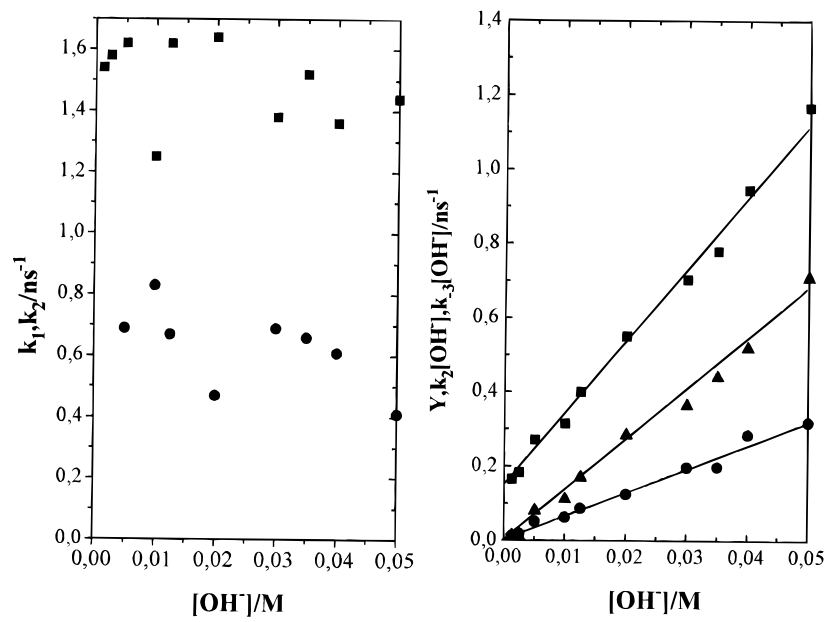

Figure 6. Plots of: (a) $k_{1}(\bullet)$ and $k_{2}(\boldsymbol{\square})$ and (b) $Y(\boldsymbol{\square}), k_{-2}\left[\mathrm{H}_{2} \mathrm{O}\right](\boldsymbol{\bullet})$ and $k_{-3}\left[\mathrm{H}_{2} \mathrm{O}\right](\boldsymbol{\Delta})$ values obtained from the analysis of time resolved data, as a function of $\left[\mathrm{OH}^{-}\right]$.

TABLE 2: Rate Constants $(k)$ and Intercepts $(a)$ and Slopes (b) of $\phi_{m} / \phi_{n}$ vs $\left[\mathrm{OH}^{-}\right]$from Time-Resolved and Steady-State Fluorescence Data

\begin{tabular}{llcc}
\hline $\begin{array}{c}\text { rate constants, } \\
\text { intercepts, } \\
\text { and slopes }\end{array}$ & $\begin{array}{c}\text { time-resolved } \\
\text { data (analytical } \\
\text { solution) }\end{array}$ & $\begin{array}{c}\text { time-resolved } \\
\text { data (numerical } \\
\text { solution) }\end{array}$ & $\begin{array}{c}\text { steady- } \\
\text { state } \\
\text { data }\end{array}$ \\
\hline$k_{1} / \mathrm{ns}^{-1}$ & 0.62 & 0.60 & \\
$k_{2} / \mathrm{ns}^{-1}$ & 1.48 & 1.32 & \\
$k_{-2} / \mathrm{L} \mathrm{mol}^{-1} \mathrm{~ns}^{-1}$ & 6.7 & 8.9 & \\
$k_{-3} / \mathrm{L} \mathrm{mol}^{-1} \mathrm{~ns}^{-1}$ & 13.4 & 12.5 & \\
$a_{\mathrm{N} / \mathrm{C}}$ & $0.096 \times k_{\mathrm{f}}^{\mathrm{N}} / k_{\mathrm{f}}^{\mathrm{C}} b$ & & 0.1 \\
$b_{\mathrm{N} / \mathrm{C}}$ & $13.85 \times k_{\mathrm{f}}^{\mathrm{N}} / k_{\mathrm{f}}^{\mathrm{C}} b$ & & 14.3 \\
$b_{\mathrm{N} / \mathrm{C}} / a_{\mathrm{N} / \mathrm{C}}$ & 146 & & 143 \\
$a_{\mathrm{Z} / \mathrm{C}}$ & $0.839 \times k_{\mathrm{f}}^{\mathrm{Z}} / k_{\mathrm{f}}^{\mathrm{C}} c$ & & 0.29 \\
$b_{\mathrm{Z} / \mathrm{C}}$ & $324 \times k_{\mathrm{f}}^{\mathrm{Z}} / k_{\mathrm{f}}^{\mathrm{C}}{ }$ & & 114 \\
$b_{\mathrm{Z} / \mathrm{C}} / a_{\mathrm{Z} / \mathrm{C}}$ & 375 & & 389
\end{tabular}

${ }^{a}$ Values determined for $k_{\mathrm{f}}^{\mathrm{N}} / k_{\mathrm{f}}^{\mathrm{C}}$ and $k_{\mathrm{f}}^{\mathrm{Z}} / k_{\mathrm{f}}^{\mathrm{C}}$ are 1.04 and 0.35 , respectively. ${ }^{b}$ From substitution of rate constants in eq 12. ${ }^{c}$ From substitution of rate constans in eq 13 .

unquenched fluorescence lifetime of the neutral form $\tau_{\mathrm{N}}=4.9$ ns (dioxane:water 3:2 mixture). The results are plotted in Figure 6 (see also Table 2).

In Figure 6b, plots of $Y$ (from eq 32), $k_{-2}\left[\mathrm{OH}^{-}\right]$(eq 31), and $k_{-3}\left[\mathrm{OH}^{-}\right]$(eq 33) as a function of $\left[\mathrm{OH}^{-}\right]$are linear, which is in agreement with the predictions of the model (Scheme 1), and it is also a clear indication of reasonable agreement between the results obtained at different $\left[\mathrm{OH}^{-}\right]$concentrations. From the slope of $Y \mathrm{vs}\left[\mathrm{OH}^{-}\right]$, a value of $k_{-2}+k_{-3}=2.05 \times 10^{10} \mathrm{~L}$ $\mathrm{mol}^{-1} \mathrm{~s}^{-1}$ was obtained, and from the intercept the value of the cation fluorescence lifetime, $\tau_{\mathrm{C}}=7.1 \mathrm{~ns}$, was recovered. The slopes of the other two plots, $\mathrm{k}_{-3}=1.34 \times 10^{10} \mathrm{~L} \mathrm{~mol}^{-1} \mathrm{~s}^{-1}$ and $k_{-2}=0.66 \times 10^{10} \mathrm{~L} \mathrm{~mol}^{-1} \mathrm{~s}^{-1}$, are compatible, respectively, with a diffusion-controlled deprotonation of the cation to yield the zwitterion $\left(k_{-3}\right)$ and a partially diffusion-controlled deprotonation back to the neutral form $\left(k_{-2}\right)$. 
TABLE 3: Experimental and Calculated $S_{1} \leftarrow S_{0}$ Transition Energies, Calculated Dipole Moments, $\mu$, Formation Enthalpies, $\Delta H_{\mathrm{f}}$, and Charge Densities on the Pyridine and the Pyrrole Nitrogens and Acidic Hydrogen Atoms of the Neutral, Cationic, and Zwitterionic Forms of Harmine, in the Ground State $(\mathbf{N}, \mathbf{C}$, and $\mathbf{Z})$ and in the Singlet Excited State $\left(\mathbf{N}^{*}, \mathbf{C}^{*}\right.$, and $\left.\mathbf{Z}^{*}\right)$

\begin{tabular}{lcccccccc}
\hline & $E_{\text {expt }}(\mathrm{eV})$ & $E_{\text {calcd }}(\mathrm{eV})$ & $\Delta H_{\mathrm{f}}(\mathrm{eV})$ & $\mu(\mathrm{D})$ & $\mathrm{N}_{\text {pyd }}(\mathrm{e})$ & $\mathrm{H}_{\text {pyd }}(\mathrm{e})$ & $\mathrm{N}_{\text {pyl }}(\mathrm{e})$ & $\mathrm{H}_{\text {pyl }}(\mathrm{e})$ \\
\hline $\mathrm{N}$ & 3.74 & 3.76 & 0.43 & 2.68 & -0.215 & & -0.209 & 0.186 \\
$\mathrm{~N}^{*}$ & & & 4.01 & 2.49 & -0.262 & & -0.098 \\
$\mathrm{C}$ & \multirow{2}{*}{3.35} & & 4.19 & & -0.153 & 0.235 & -0.226 \\
$\mathrm{C}^{*}$ & & & 9.91 & & -0.211 & 0.235 & -0.225 \\
$\mathrm{Z}$ & & 2.51 & 1.30 & 5.58 & -0.174 & 0.199 & 0.237 \\
$\mathrm{Z}^{*}$ & & & 3.82 & 3.42 & -0.197 & 0.199 & -0.136
\end{tabular}

In Figure 6a, $k_{1}$ (from eq 35) for $\mathrm{N}^{*} \rightarrow \mathrm{Z}^{*}$ and $k_{2}$ (eq 34) for $\mathrm{N}^{*} \rightarrow \mathrm{C}^{*}$ are also plotted as a function of $\left[\mathrm{OH}^{-}\right]$. These plots show a larger dispersion of results than those in Figure $6 \mathrm{~b}$ which is due to the major influence of $\lambda_{3}$ on the value of $k_{1}+k_{2}$. Note that an accuracy of $\tau_{3}$, better than that attainable with our equipment $( \pm 20 \mathrm{ps})$, would be required to reduce that scatter. Under these conditions, we are only sure that both $k_{1}$ and $k_{2}$ do not depend to any significant degree on the $\mathrm{pH}$. It is also noticeable that $k_{1}$, which involves a concerted double proton transfer, is not much smaller than $k_{2}$. A similar result was previously observed for the excited state tautomerization of 4-methyl-7-hydroxycoumarin. ${ }^{19}$

In Table 2, the experimental slopes $\left(a_{X / \mathrm{C}}\right)$, intercepts $\left(b_{X / \mathrm{C}}\right)$, and slope/intercept ratios of $\phi_{\mathrm{N}} / \phi_{\mathrm{C}}$ and $\phi_{\mathrm{Z}} / \phi_{\mathrm{C}}$ vs $\left[\mathrm{OH}^{-}\right]$(steadystate data) are compared to those calculated using the timeresolved data in eqs 12 and 13 . Very good agreement between the experimental and the calculated slope/intercept ratios $b / a$ is observed, Table 2 . The ratios of the radiative rate constants determined from the experimental and the calculated slopes $\left(k_{\mathrm{f}}^{\mathrm{N}} / k_{\mathrm{f}}^{\mathrm{C}}=1.03\right.$ and $\left.k_{\mathrm{f}}^{\mathrm{Z}} / k_{\mathrm{f}}^{\mathrm{C}}=0.35_{2}\right)$ are in excellent agreement with those evaluated from the experimental and calculated intercepts $\left(k_{\mathrm{f}}^{\mathrm{N}} / k_{\mathrm{f}}^{\mathrm{C}}=1.04\right.$ and $\left.k_{\mathrm{f}}^{\mathrm{Z}} / k_{\mathrm{f}}^{\mathrm{C}}=0.34_{6}\right)$, Table 2. With these values, the radiative rate constants of the neutral and the zwitterion were redetermined (note that we have assumed that $k_{\mathrm{f}}^{\mathrm{N}}$ in dioxane $\left(0.098 \mathrm{~ns}^{-1}\right)$ is equal to $k_{\mathrm{f}}^{\mathrm{N}}$ in water $\left(0.072 \mathrm{~ns}^{-1}\right)$ and that $k_{\mathrm{f}}^{\mathrm{Z}}$ was evaluated using $k_{\mathrm{f}}^{\mathrm{N}}$ ). Comparison between these values and the experimental ones (Table 2) shows that only $k_{\mathrm{f}}^{\mathrm{N}}$ is significantly affected in a way that is predictable on the basis of the refractive indexes of the solvents ( $n_{\mathrm{D}}$ (dioxane) $=1.437$ and $\left.n_{\mathrm{D}}\left(\mathrm{H}_{2} \mathrm{O}\right)=1.383\right)$. This implies that the unquenched lifetime of the neutral form in water needs to be corrected accordingly (a value of $\tau_{\mathrm{N}}^{\circ}=5.3 \mathrm{~ns}$ is estimated). However, this correction did not affect the results of the analysis of the time-resolved data because $\lambda_{3}=k_{1}+k_{2}+1 / \tau_{\mathrm{N}} \sim 6.7 \mathrm{~ns}$ ${ }^{-1}$ is much larger than $1 / \tau_{\mathrm{N}}^{\circ} \sim 0.2 \mathrm{~ns}^{-1}$.

For comparison purposes, the results obtained from the analysis of the time-resolved data with a previously reported numerical method of analysis ${ }^{19}$ are also shown in Table 2. Reasonably good agreement between the two sets of results is observed.

Rate Constants and Results from Molecular Orbital Calculations. The theoretical formation enthalpies $\left(\Delta H_{\mathrm{f}}{ }^{\circ}\right)$, dipole moments $(\mu), \mathrm{S}_{0} \rightarrow \mathrm{S}_{1}$ transition energies, $\left(E\left(\mathrm{~S}_{0} \rightarrow \mathrm{S}_{1}\right)\right)$, and the charge densities on the nitrogen and acidic hydrogen atoms of the pyrrole and pyridine rings of the three harmine forms, both in the ground and in the excited states, are given in Table 3. First note that the formation enthalpy of the ground state zwitterion is about $0.9 \mathrm{eV}$ higher in energy than that of the neutral form, but in the excited state it is $0.2 \mathrm{eV}$ lower. This nicely explains why the zwitterion is detected and can exist only in the excited state. The same conclusion can be reached from the analysis of the charge densities on the nitrogen atoms; in particular, note the increase in electron charge density on the pyridine nitrogen going from the ground state $\mathrm{N}(-0.215)$ to the first excited state $\mathrm{N}^{*}(-0.262)$ and the notable decrease in electron charge density on the pyrrole nitrogen atom, going from $\mathrm{N}(-0.209)$ to $\mathrm{N}^{*}(-0.098)$ (also see ref 6). These changes on the pyridine and pyrrole nitrogen atoms have implications regarding the mechanism of $Z^{*}$ formation. Two possibilities exist: (1) a push-pull double proton transfer involving $\mathrm{N}^{*}$ and (2) formation of the excited state anion, $\mathrm{A}^{*}$, by $\mathrm{H}^{+}$transfer from the pyrrole nitrogen of $\mathrm{N}^{*}$ to water followed by $\mathrm{H}^{+}$transfer to $\mathrm{A}^{*}$ from water to the pyridine nitrogen (to give $\mathrm{Z}^{*}$ ). On the time scale of the current study, neither mechanism could be observed since the $\mathrm{N}^{*} \rightarrow \mathrm{A}^{*}$ process and the lifetime of $A^{*}$ would be expected to be very fast (picosecond). We plan to explore this problem with picosecond time resolution.

This large change on the pyridine nitrogen charge also rationalizes the formation of $\mathrm{C}^{*}$ (from $\mathrm{N}^{*}$ ) and the high rate constant for $k_{2}, \mathrm{~N}^{*}\left(+\mathrm{H}_{2} \mathrm{O}\right) \rightarrow \mathrm{C}^{*}\left(+\mathrm{OH}^{-}\right)$. At the same time the large decrease in charge density on the pyrrole nitrogen permits us to predict an efficient formation of the $Z^{*}$. On the other hand, it is not surprising that $k_{1}\left(\mathrm{~N}^{*} \rightarrow \mathrm{Z}^{*}\right)$ is smaller than $k_{2}\left(\mathrm{~N}^{*} \rightarrow \mathrm{C}^{*}\right)$ since we would expect that a double proton transfer mechanism would be slower than a single proton transfer (to form $\mathrm{C}^{*}$ ).

On the other hand, once the $\mathrm{C}^{*}$ is formed, as indicated by the charge densities, the pyrrole $\mathrm{N}-\mathrm{H}$ bond would become stronger. Given this situation and by comparison to that of $\mathrm{N}^{*}$ and $\mathrm{Z}^{*}$ where both show a large decrease of charge density on the pyrrole $\mathrm{N}$, we would not expect $\mathrm{C}^{*}$ to go to either $\mathrm{N}^{*}$ or $\mathrm{Z}^{*}$ with an appreciable rate constant when $\left[\mathrm{OH}^{-}\right]=0$. Only in the presence of a much stronger base than $\mathrm{H}_{2} \mathrm{O}$ such as $\mathrm{OH}^{-}$, would we expect to have appreciable values of both $k_{-3}$ $\left(\mathrm{C}^{*}\left(+\mathrm{OH}^{-}\right) \rightarrow \mathrm{Z}^{*}\right)$ and $k_{-2}\left(\mathrm{C}^{*}\left(+\mathrm{OH}^{-}\right) \rightarrow \mathrm{N}^{*}\right)$.

Finally, in the cases of $k_{-1}\left(\mathrm{Z}^{*} \rightarrow \mathrm{N}^{*}\right)$ and $k_{3}\left(\mathrm{Z}^{*} \rightarrow \mathrm{C}^{*}\right)$, we would not expect these to substantially occur since the charge density on the pyrrole nitrogen of $\mathrm{Z}^{*}$ is so low that $\mathrm{N}-\mathrm{H}$ bond formation would be unlikely (as was found experimentally).

We can also use literature data to verify some of these expectations. Consider the $\mathrm{C}^{*}+\mathrm{OH}^{-} \leftrightarrow \mathrm{Z}^{*}$ equilibrium, for which $\mathrm{p} K^{*} \mathrm{CZ}=6.0 .^{8}$ Using our value of $k_{-3}=1.48 \times 10^{10} \mathrm{~L}$ $\mathrm{mol}^{-1} \mathrm{~s}^{-1}$, we estimate for the rate constant of the process $\mathrm{Z}^{*}$ $\rightarrow \mathrm{C}^{*}$ a value of $k_{3}=1.5 \times 10^{4} \mathrm{~s}^{-1}$, which obviously is much smaller than $1 / \tau_{\mathrm{Z}}=2.86 \times 10^{8} \mathrm{~s}^{-1}$; thus $k_{3}=0$ under the experimental conditions. We can also make a good estimate of the $\mathrm{p} K^{*}{ }_{\mathrm{CN}}=14-\log \left(k_{-2} / k_{2}\right)=13.35$, which is similar to the reported values of $12.9,{ }^{8} 14.7,{ }^{10} 12.5,{ }^{7}$ and $13.1^{9}$ (vs ground state values of $7.7,{ }^{7} 7.9,{ }^{10}$ and $8.0^{8}$ ).

\section{Summary/Conclusions}

1. From a combination of absorption, emission, and decay data, it has been possible to develop a model for the excited state dynamics of neutral, zwitterionic and cationic harmine.

2. A methodology to evaluate all the rate constants involved in the mechanism using both a numerical and an analytical procedure has been developed.

3. Implementation of that methodology has shown that despite its theoretical simplicity, highly accurate time-resolved 
data is required and it must be coupled to steady state data to evaluate the rate-constants with acceptable confidence.

4. Excitation of neutral harmine $(\mathrm{N})$ results in formation of $\mathrm{N}^{*}$ which can then produce the cation $\left(\mathrm{C}^{*}\right)$ and the zwitterion excited state $\left(\mathrm{Z}^{*}\right)$ during the lifetime of $\mathrm{N}^{*}$. The ground state neutral species $(\mathrm{N})$ exists only above $\sim \mathrm{pH}=7$.

5. The $\mathrm{N}^{*}$ has a fluorescence maximum at $350 \mathrm{~nm}$ with a lifetime ( $0.41 \mathrm{~ns})$ approximately 10 -fold shorter than in nonprotic solvents, indicating quenching of $\mathrm{N}^{*}$ by water.

6. The $\mathrm{C}^{*}$ has a fluorescence maximum at $400 \mathrm{~nm}$ with a decay time (7.1 ns) approximately 17 -fold longer than that of $\mathrm{N}^{*}$. The $\mathrm{C}^{*}$ can be produced by either excitation of $\mathrm{N}$ or $\mathrm{C}$ itself which exists from $\mathrm{pH} 1-9.5$. At sufficiently high $\mathrm{pH}$, $\mathrm{C}^{*}$ is deprotonated (by $\mathrm{OH}^{-}$) to give $\mathrm{N}^{*}$.

7. The zwitterion has only been detected in the excited state, $\mathrm{Z}^{*}$. Below $\mathrm{pH}=9$, the $\mathrm{Z}^{*}$ is formed from $\mathrm{N}$ (via $\mathrm{N}^{*}$ ) exclusively by a double proton transfer mechanism. The $\mathrm{Z}^{*}$ back-reaction to give $\mathrm{N}^{*}$ is extremely slow compared with the decay of $\mathrm{Z}^{*}$. At sufficiently high $\mathrm{pH}, \mathrm{Z}^{*}$ is also formed from $C^{*}$. The $Z^{*}$ does not return in a back-reaction to give $C^{*}$. The lifetime of $Z^{*}$ is the longest of all tautomers $(\sim 14 \mathrm{~ns})$. Calculations show that the $\Delta H_{\mathrm{f}}$ of $\mathrm{Z}$ would be notably higher than that of $\mathrm{N}$, while $\Delta H_{\mathrm{f}}$ of $\mathrm{Z}^{*}$ is notably lower than that of $\mathrm{N}^{*}$, thus rationalizing the observation/existence of the zwitterion only in the excited state $\left(\mathrm{Z}^{*}\right)$.

8. Charge density calculations in the $S_{0}$ and $S_{1}$ states for the $\mathrm{N}$ rationalize the formation of $\mathrm{C}^{*}$ from $\mathrm{N}^{*}$ since there is a notable increase of negative charge on the pyridine $\mathrm{N}$ atom in the $S_{1}$ state. Also, there is a notable decrease of negative charge on the pyrrole $\mathrm{N}$ atom in the $\mathrm{S}_{1}$ state which can rationalize the formation of $\mathrm{Z}^{*}$ from $\mathrm{N}^{*}$.

9. The reactions of $\mathrm{C}^{*}$ with $\mathrm{OH}^{-}$

$$
N^{*} \stackrel{k_{-2}\left[\mathrm{OH}^{-}\right]}{\stackrel{k_{3}\left[\mathrm{OH}^{-}\right]}{\longrightarrow}} \mathrm{Z}^{*}
$$

have noticeably different rate constants of formation of $N^{*}(0.66$ $\left.\times 10^{10} \mathrm{~L} \mathrm{~mol}^{-1} \mathrm{~s}^{-1}\right)$ and formation of $\mathrm{Z}^{*}\left(1.34 \times 10^{10} \mathrm{~L} \mathrm{~mol}^{-1}\right.$ $\mathrm{s}^{-1}$; nearly diffusion controlled). This suggests a difference in the activation energy for the reaction of $\mathrm{OH}^{-}$with $\mathrm{H}^{+}$on the pyrrole nitrogen atom vs that on the pyridine nitrogen atom.

Acknowledgment. This work was supported by JNICTPortugal (Project STRDA/C/AMB/40/92). A.P.V. also gratefully acknowledges JNICT for a Ph.D. grant (No. BD/1680/ 91-IF).

\section{References and Notes}

(1) Dymock, W. Pharmacographia Indica 1890, 71 (republished by the Institute of Health and Tibbi Research).

(2) Chopra, R. N.; Nayar, S. L.; Chopra, I. C. Glossary of Indian Medicinal Plants; Council of Scientific and Industrial Research: New Delhi, 1956; p 187.

(3) Codding, P. W. Can. J. Chem. 1983, 61, 529.

(4) Shoemaker, O. W.; Bidder, T. G.; Boettger, H. G.; Cummins, J. T.; Evans, M. J. Chromatogr. 1979, 174, 159.

(5) Mc Kenna, D. J.; Towers, G. H. N.; Phytochemistry 1981, 20, 1001.

(6) Dias, A.; Varela, A. P.; Miguel, M.; Maçanita, A. L.; Becker, R. S. J. Phys. Chem. 1992, 96, 10290.

(7) Wolfbeis, O. S.; Furlinger, E., Monatsh. Chem. 1982, 113, 509.

(8) Vert, F. T.; Sanchez, I. Z.; Torrent, A. O. J. Photochem. 1983, 23

(9) Balón, M.; Hidalgo, J.; Guardado, P.; Muñoz, M. A.; Carmona, C. J. Chem. Soc., Perkin Trans. 2 1993, 91, 99.

(10) Sakurovs, R.; Ghiggino K. P. J. Photochem. 1982, 18, 1.

(11) Ghiggino, K. P.; Skilton, P. F., Thistlewaite P. J. J. Photochem. 1985, 31,113 .

(12) Pardo, A.; Reyman, D.; Martin, E.; Royato, J. M.; Camacho, J. J. J. Lumin. 1988, 42, 163.

(13) Draxler, S.; Lippitch, M. E. J. Phys. Chem. 1993, 97, 11493.

(14) Varela, A. P.; Dias, A.; Miguel, M.; Becker, R. S.; Maçanita, A. L. J. Phys. Chem. 1995, 99, 2239.

(15) Maçanita, A. L.; Costa, F. P.; Costa, S. M. B.; Melo, E. C.; Santos, H. J. Phys. Chem. 1989, 93, 336.

(16) Zachariasse, K.; Duveneck, G.; Busse, R. J. Am. Chem. Soc. 1984, 106, 1045 .

(17) Striker, J., Jr. Deconvolution and Reconvolution of Analytical Signals; Bouchy, M., Ed.; University Press: Nancy, France, 1982; p 329.

(18) Moriya, T. Bull. Chem. Soc. Jpn. 1988, 61, 1873.

(19) Melo, J. S.; Maçanita, A. L. Chem. Phys. Lett., 1993, 204, 556.

JP961406U 